\title{
Root Canal Irrigants in Horizon: A Review
}

\author{
Snigdha Thakur
}

\begin{abstract}
Local wound debridement in the diseased pulp space is the main step in root canal treatment to prevent the tooth from being a source of infection. Successful root canal therapy is always based on the combination of proper instrumentation, irrigation and obturation of the root canal. Of these three essential steps of root canal therapy, irrigation of the root canal is the most important technique which aids in the healing of the periapical tissues. The root canal is shaped under constant irrigation to remove the inflamed and necrotic tissue, microbes, biofilms and other debris from the root canal space. There is no single irrigating solution that can alone cover all of the functions required from an irrigant. Optimal irrigation is based on the combined use of two or several irrigating solutions, in a proper sequence, to predictably obtain the goals of safe and effective irrigation. This article highlights various irrigants, ideal requirements of irrigants and newer irrigants used for irrigation.
\end{abstract}

Keywords: Irrigation, Endodontics, Disinfection

\section{Introduction}

Bacteria in the root canal system provoke the formation of periapical inflammatory lesions (1). The aim of root canal treatment is to eliminate bacteria from the infected root canal and to prevent re-infection. Biomechanical cleaning and shaping of the root canal greatly reduces the number of bacteria (2). Nevertheless, studies have shown that bacteria often persist (3) Therefore, irrigation with strong antibacterial agents is imperative to complete the cleaning and shaping process.

Irrigants have traditionally been delivered into the rootcanal space using syringes and metal needles of different size and tip design. Clinical experience and research have shown, however, that this classic approach typically results in ineffective irrigation. It is the purpose of this article to present an overview on irrigating solutions in endodontics and some new devices to improve the delivery to the apical portion of the root canal system.

To comprehend how irrigation works, it is important to understand the two main objectives of irrigation: mechanical and biological. The mechanical objective involves the following: 1 . flushing out debris, 2 . lubricating the canal, 3. dissolving organic and inorganic tissue. The biological function of the irrigants is related to their antimicrobial effect (4).

The biological function of the irrigants is related to their antimicrobial effect. The ideal endodontic irrigant should possess the following characteristics (5): be an effective germicide and fungicide, be non-irritating to the periapical tissues, remain stable in solution, have a prolonged antimicrobial effect, be active in the presence of blood, serum, and protein derivates of tissue, have low surface tension, should not interfere with repair of periapical tissues, not stain tooth structure, be capable of inactivation in a culture medium, should not induce a cell mediated immune response.

None of the available irrigating solutions can be regarded as optimal. Using a combination of products in the correct irrigation sequence and technique contributes to a successful treatment outcome.

\section{Sodium Hypochlorite}

Sodium hypochlorite $(\mathrm{NaOCl})$ is the most commonly used irrigating solution. It is an excellent antibacterial agent, able to dissolve necrotic and vital pulp tissue, the organic components of dentin as well as biofilms (6).

\section{Mode of Action}

When hypochlorite contacts tissue proteins, nitrogen, formaldehyde, and acetaldehyde are formed within a short time, hydrogen in the imino groups (-NH-) is replaced by chlorine (-N.Cl-) forming chloramines, which plays an important role for the antimicrobial effectiveness. Thus, the necrotic tissue and pus are dissolved. Sodium hypochlorite is a strong base $(\mathrm{pH}>11)$. Temperature increase will significantly improve the antimicrobial effect of sodium hypochlorite (7). $\mathrm{NaOCl}$ exhibits a dynamic balance that acts as an organic and fat solvent degrading fatty acids, transforming them into salts (soap) and glycerol (alcohol), that reduces the surface tension of the remaining solution (saponification reaction).

\section{Concentrations}

There is considerable variation in the literature regarding the effective concentration of $\mathrm{NaOCl}$ as an endodontic irrigant. $\mathrm{NaOCl}$ is used in concentrations between 0.5 and $5.25 \%$ solutions. Clinical studies have shown both low and high concentrations to be equally effective in reducing bacteria from the root canal system (8). NaOCl in higher concentrations has a better tissue-dissolving ability, however, even in lower concentrations when used in high volumes it can equally be effective. Higher concentrations of $\mathrm{NaOCl}$ are more toxic than lower concentrations.

\section{Tissue Dissolution Capacity}

The dissolution of bovine pulp tissue by $\mathrm{NaOCl}(0.5,1.0$, 2.5 , and $5.0 \%$ ) was studied in vitro under different conditions. It was concluded that: 1) the velocity of dissolution of the bovine pulp fragments was directly proportional to the concentration of the $\mathrm{NaOCl}$ solution and was greater without the surfactant; 2) with elevation of temperature, dissolution of the bovine pulp tissue was more rapid; 3) the greater the initial concentration, the smaller was the reduction of its $\mathrm{pH} 10$. 


\section{International Journal of Science and Research (IJSR) \\ ISSN (Online): 2319-7064 \\ Index Copernicus Value (2013): 6.14 | Impact Factor (2014): 5.611}

Safety

Several mishaps during root canal irrigation have been described in the dental literature. These range from damage to the patient's clothing, splashing the irrigant into the patient's or operator's eye, injection through the apical foramen, and allergic reactions to the irrigant, to inadvertent use of an irrigant as an anesthetic solution

\section{Chlorhexidine Gluconate}

Chlorhexidine gluconate (CHX) is a broad-spectrum antimicrobial agent that has been advocated for root canal disinfection (9). When used as an irrigant or intracanal medication, its antibacterial efficacy is comparable to that of $\mathrm{NaOCl}$, and it is effective against certain $\mathrm{NaOCl}-$ resistant bacterial strains. Prolonged exposure of the root dentin to CHX may impart a residual antimicrobial property to the dentin surface. CHX has a low grade of toxicity; however, its inability to dissolve organic matter maybe a drawback in its clinical use.

\section{Mode of Action}

CHX is a wide-spectrum antimicrobial agent, active against Gram-positive and Gram-negative bacteria, and yeasts (10).Due to its cationic nature, CHX is capable of electrostatically binding to the negatively charged surfaces of bacteria, damaging the outer layers of the cell wall and rendering it permeable. Depending on its concentration, CHX can have both bacteriostatic and bactericidal effects. At high concentration CHX acts as a detergent, and by damaging the cell membrane it causes precipitation of the cytoplasm and thereby exerts a bactericidal effect.

\section{Chlorhexdine Application in Endodontics}

In endodontics, $\mathrm{CHX}$ has been studied as an irrigant and intracanal medication, both in vivo (11) and in vitro (12) In vitro, $\mathrm{CHX}$ has at least as good, or even better antimicrobial efficacy than $\mathrm{Ca}(\mathrm{OH}) 2$. Notably, 2\% CHX was very effective in eliminating a biofilm of E. faecalis. In vivo, it inhibits experimentally-induced inflammatory external root resorption when applied for four weeks.

In infected root canals, it reduces bacteria as effectively as $\mathrm{Ca}(\mathrm{OH}) 2$ when applied for one week. Unlike $\mathrm{Ca}(\mathrm{OH}) 2$, CHX has substantive antimicrobial activity that, if imparted onto the root dentin, has the potential to prevent bacterial colonization of root canal walls for prolonged periods of time.

\section{EDTA, Citric Acid}

EDTA is normally used in a concentration of $17 \%$. It removes smear layers in less than 1 minute if the fluid is able to reach the surface of the root canal wall. The decalcifying process is self-limiting, because the chelator is used up. Although citric acid appears to be slightly more potent at similar concentration than EDTA, both agents show high efficiency in removing the smear layer. In addition to their cleaning ability, chelators may detach biofilms adhering to root canal walls. This may explain why an EDTA irrigant proved to be highly superior to saline in reducing intracanal microbiota, despite the fact that its antiseptic capacity is relatively limited.

Antiseptics such as quaternary ammonium compounds (EDTAC) or tetracycline antibiotics (MTAD) have been added to EDTA and citric acid irrigants, respectively, to increase their antimicrobial capacity. The clinical value of this, however, is questionable. EDTAC shows similar smear-removing efficacy as EDTA, but it is more caustic. Chelating agents can be applied in liquid or paste-type form. Urea peroxide is usually used as a vehicle. Research is showing that instead of lowering physical stress on rotary instruments as advocated, carbowax-based lubricants, depending on instrument geometry, have either no effect or are even counterproductive.

\section{Q Mix}

Q mix is an irrigation solution used as a final rinse. It is a combination of CHX with EDTA and a surfactant solution to improve penetration in dentinal tubules.

\section{MTAD}

A compound has been developed with combined chelating and antibacterial properties (13). MTAD (BioPure MTAD; Dentsply Tulsa Dental Specialties, Tulsa, OK) is a mixture of doxycycline, citric acid, and Tween. It is applied as a 5minute final rinse after canal instrumentation and irrigation with $1.3 \% \mathrm{NaOCl}$ 47. Preliminary in vitro studies have suggested effective elimination of root canal bacteria by MTAD (14)

\section{Herbal}

\section{Triphala}

Triphala consists of dried and powdered fruits of three medicinal plants Terminalia bellerica, Terminalia chebula, and Emblica officinalis (15). Triphala achieved 100\% killing of E faecalis at 6 min. This may be attributed to its formulation, which contains three different medicinal plants in equal proportions; in such formulations, different compounds may help enhance the potency of the active compounds, producing an additive or synergistic effect. Triphala contains fruits that are rich in citric acid, which may aid in removal of the smear layer. The major advantages of using herbal alternatives are easy availability, cost-effectiveness longer shelf life, low toxicity, and lack of microbial resistance.

\section{Green Tea}

Green tea polyphenols, the traditional drink of Japan and China is prepared from the young shoots of the tea plant Camellia sinensis (16). Green tea polyphenols showed statistically significant antibacterial activity against E faecalis biofilm formed on tooth substrate. It takes $6 \mathrm{~min}$ to achieve $100 \%$ killing of E faecalis [102].

Dimethyl sulfoxide (DMSO) is used as a solvent for Triphala and GTP, although they are readily soluble in 


\section{International Journal of Science and Research (IJSR) \\ ISSN (Online): 2319-7064 \\ Index Copernicus Value (2013): 6.14 | Impact Factor (2014): 5.611}

water. DMSO is a clean, safe, highly polar, aprotic solvent that helps in bringing out the pure properties of all the components of the herb being dissolved.

\section{New Irrigation and Disinfection Techniques and Devices}

Many techniques and devices have been proposed to increase the flow and distribution of irrigating solutions within the root canal system. Because of the intricate nature of root canal anatomy chemomechanical cleaning and shaping are not enough to predictable eliminate bacterial loads from fins, lateral canals and even deltas at the apical portion.

Conventional syringes with various needles diameter, manual brushes and fitted gutta percha cones are suggested as a manual method to get the irrigant deep in the canal. Other than these conventional irrigation techniques, additional techniques for disinfection of the endodontic cavity have been proposed and tested, including laser systems and gaseous ozone. Recently several new devices for endodontic irrigation and/or disinfection have been introduced, among which are The Self Adjusting File (SAF, ReDent, Raanana, Israel), the Endoactivator System (DENTSPLY Tulsa Dental Specialties), Passive ultrasonic irrigation and EndoVac (Discus, Culver City, CA, USA).

\section{Maunal Dynamic Irrigation}

Manual dynamic irrigation has been described as a costeffective technique for cleaning the walls of the entire root canal. It involves repeated insertion of a well-fitting guttapercha cone to working length of a previously shaped canal. The gutta-percha cone is applied in short, gentle strokes to hydrodynamically displace and activate an irrigant.

\section{Passive Ultrasonic Irrigation}

Ultrasonic irrigation of the root canal can be performed with or without simultaneous ultrasonic instrumentation. When canal shaping is not undertaken, the term passive ultrasonic irrigation (PUI) can be used to describe the technique. Passive ultrasonic irrigation can be performed with a small file or smooth wire (size 10-20) oscillating freely in the root canal to induce powerful acoustic microstreaming. PUI can be an important supplement for cleaning the root canal system and, compared with traditional syringe irrigation; it removes more organic tissue, planktonic bacteria and dentine debris from the root canal. PUI is more efficient in cleaning canals than ultrasonic irrigation with simultaneous ultrasonic instrumentation. PUI can be effective in curved canals and a smooth wire can be as effective as a cutting K-file. The taper and the diameter of the root canal were found to be important parameters in determining the efficacies of dentine debris removal. Irrigation with sodium hypochlorite is more effective than with water and ultrasonic irrigation is more effective than sonic irrigation in the removal of dentine debris from the root canal. The role of cavitation during PUI remains inconclusive. No detailed information is available on the influence of the irrigation time, the volume of the irrigant, the penetration depth of the instrument and the shape and material properties of the instrument (17).

\section{ENDO VAC}

An irrigation system called EndoVac (Discus Dental, Culver City, CA) might better deliver the irrigant to apical areas of canals and into root canal irregularities. The EndoVac system uses a suction needle placed at working length (WL). With negative pressure, the irrigant flows down from the pulp chamber into the canal to the apical areas. A study by Nielsen and Baumgartner showed significantly better debridement at $1 \mathrm{~mm}$ from WL on extracted teeth by using the EndoVac compared with conventional needle irrigation. Shin et al. also showed that the EndoVac left significantly less debris behind than conventional needle irrigation (18).

\section{Suggested Irrigation Regimen}

A hypochlorite solution should be employed throughout instrumentation, without altering it with EDTA or citric acid. Between instruments, canals should be irrigated using copious amounts of the hypochlorite solution. Once the shaping procedure is completed, canals can be thoroughly rinsed using aqueous EDTA or citric acid. Generally each canal is rinsed for at least 1 min using 5 to $10 \mathrm{ml}$ of the chelator irrigant. After the smear layer removal procedure, a final rinse with an antiseptic solution appears beneficial. Chlorhexidine appears to be the most promising agent for use as a final irrigant in this situation. It has an affinity for dental hard tissues and, once bound to a surface, it has prolonged antimicrobial activity, a phenomenon called substantivity. After the introduction of MTAD irrigant, newer irrigating regimen followed was initial rinse with $1.3 \% \mathrm{NaOCl}$ for $20 \mathrm{~min}$ and followed by final rinse with MTAD for $5 \mathrm{~min}$. Future research on irrigants needs to focus on finding a single irrigant that has tissue dissolving capacity, smear layer removal property, and antibacterial efficacy.

\section{References}

[1] Kakehashi S, Stanley HR, Fitzgerald RJ. The Effects of Surgical Exposures of Dental Pulps in Germ-Free and Conventional Laboratory Rats. Oral Surg Oral Med Oral Pathol 1965; 20: 340-349.

[2] Bystrom A, Sundqvist G. Bacteriologic evaluation of the efficacy of mechanical root canal instrumentation in endodontic therapy. Scand J Dent Res 1981; 89:321-328.

[3] Peters OA. Current challenges and concepts in the preparation of root canal systems: a review. J Endod 2004; 30: 559-67.

[4] Meztger Z, Basrani B, Goodis H. Instruments, Materials and Devices. In pathways of the Pulp, 8th ed, Cohen S., Hargreaves K. Elseiver. 2010.

[5] Grossman LI, Meiman BW. Solution of Pulp Tissue By Chemical Agent. J Amer Dent Ass; 1941, 28:223.

[6] Senia ES, Marshal FJ, Rosen S. The Solvent Action of Sodium Hypochlorite On Pulp Tissue Of Extracted 
Teeth. Oral Surg.Oral Med.Oral Pathol Oral Radiol Endod; 197131:96.

[7] Estrela C, Estrela C, Barbin E, Spanó J. Marchesan M, Pécora J Mechanism Of Action Of Sodium Hypochlorite, D. Braz Dent J; 2002, 13: 113.

[8] Byström A, Sundqvist G. The Antibacterial Action Of Sodium Hypochlorite And EDTA In 60 Cases Of Endodontic Therapy. Int Endod J; 1985, 18:35.

[9] Ohara P, Torabinejad M, Kettering JD. Antibacterial effects of various endodontic irrigants on selected anaerobic bacteria. Endod Dent Traumatol;1993; 9: 95-100.

[10]Denton 1991 Denton G. Chlorhexidine. In: Block SS. Disinfection, Sterilization And Preservation. 4th Ed. Philadelphia: Lea And Febiger; 1991

[11] Barbosa CA, Goncalves RB, Siqueira JF, Jr., De Uzeda M. Evaluation Of The Antibacterial Activities Of Calcium Hydroxide, Chlorhexidine, And Camphorated Paramonochlorophenol As Intracanal Medicament. A Clinical And Laboratory Study, J Endod; 1997, 23:297.

[12] Komorowski R, Grad H, Wu XY, Friedman S. Antimicrobial substantivity of chlorhexidine-treated bovine root dentin. J Endod ;2000; 26: 315-317.

[13] Malkhassian G, Manzur AJ, Legner M, Fillery ED, Manek S, Basrani BR, Friedman S. Antibacterial efficacy of MTAD final rinse and two percent chlorhexidine gel medication in teeth with apical periodontitis: a randomized double-blinded clinical trial. J Endod. 2009;35:1483-90.

[14] Newberry B.M., Shabahang S., Johnson N., Aprecio R.M., Torabinejad M., The antimicrobial effect of biopure MTAD on eight strains of Enterococcus faecalis: an in vitro investigation, J Endod ; 2007, 33:1352-1354.

[15] Jagetia GC, Baliga MS, Malagi KJ, Kamath SM. The evaluation of the radioprotective effect of Triphala (an Ayurvedic rejuvenating drug) in the mice exposed to gamma- radiation. Phytomedicine 2002;9:99-108.

[16] Younos C, Rolland A, Fleurentin J, Lanhers MC, Misslin R, et al. Analgesic and behavioural effects of Morindacitrifolia. Planta Med 1990;56:430-434.

[17] van der Sluis LW, Versluis M, Wu MK, Wesselink PR. Passive ultrasonic irrigation of the root canal: a review of the literature. Int Endod J. 2007; 40:415-26.

[18] Siu C, Baumgartner JC. Comparison of the debridement efficacy of the EndoVac irrigation system and conventional needle root canal irrigation in vivo. J Endod. 2010; 36 :1782-5 